\title{
Statistical analysis of health inequalities in the northern region of Portugal
}

Cite as: AIP Conference Proceedings 2040, 110007 (2018); https://doi.org/10.1063/1.5079171

Published Online: 30 November 2018

Lara Teixeira, Vasco Machado, A. Manuela Gonçalves, Susana Faria, and Manuela Felício

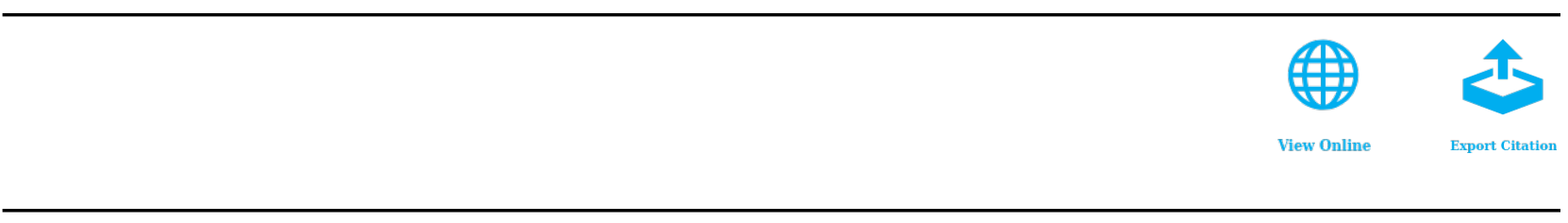

\section{Conference Proceedings}

Get $30 \%$ off all print proceedings!

\section{Enter Promotion Code PDF-30 at checkout}

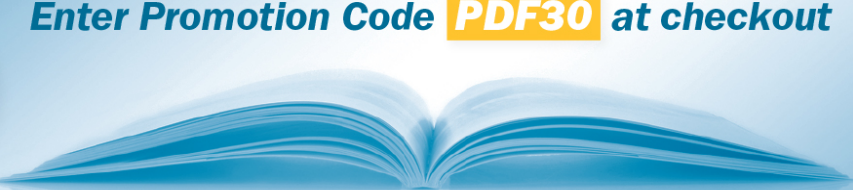




\title{
Statistical Analysis of Health Inequalities in the Northern Region of Portugal
}

\author{
Lara Teixeira $^{1,2, a)}$, Vasco Machado ${ }^{3, b)}$, A. Manuela Gonçalves ${ }^{1, c)}$, Susana Faria ${ }^{1, d)}$ \\ and Manuela Felício ${ }^{3, \text { e) }}$ \\ ${ }^{1}$ CMAT - Centre of Mathematics, Department of Mathematics and Applications, University of Minho, Portugal. \\ ${ }^{2}$ Faculty of Sciences, University of Porto, Portugal. \\ ${ }^{3}$ Northern Region Health Administration - Public Health Department, Portugal. \\ a)lara-teixeira@hotmail.com \\ b)vmachado@arsnorte.min-saude.pt \\ c) Corresponding author: mneves@math.uminho.pt \\ d) sfaria@math.uminho.pt \\ e) mfelicio@arsnorte.min-saude.pt
}

\begin{abstract}
Different public health needs demand differentiated interventions by the Health services in order to attain efficiency and thus reducing Health inequalities. The statistical model which was developed will allow the Public Health Services to conduct a diagnostic evaluation of Health inequalities, with a specification of the death causes and age groups that most contribute to those inequalities. It will also allow a prognostic evaluation by analyzing the impact of some interventions in reducing the relative gap in life expectancy, in terms of health gains.
\end{abstract}

\section{INTRODUCTION}

Reducing health inequalities is a matter of fairness and social justice. This is one of the key messages of the Marmot Review [1] and it applies to any country or region.

Health Inequalities are disparities in health results between individuals or groups. They arise due to differences in social and economic conditions that influence the behavior and lifestyle choices, as well as the risk of disease occurrence and measures taken when they occur. Thus, inequalities in these health social determinants are avoidable and therefore are considered unjust.

Inequalities can be found among various population groups, for example, disparities by gender, age, social status and ethnicity. Different population health needs require different interventions by the health services, making them more efficient and effective. The development of effective tools for the identification and analysis of inequalities in population health's is thus one outstanding challenge for the Public Health services at the regional and local levels [2].

The main goal of this project is to build a toolkit that will allow not only to identify health inequalities, but also to estimate the impact of some interventions in the reduction of these inequalities.

\section{METHODS}

Life expectancy at birth was considered as the summary measure of health status. In order to identify health inequalities, the relative life expectancy gap was used. The relative life expectancy gap is the absolute difference in life expectancy between a Reference and the Geographic Area under analysis, presented as a percentage of the Reference's life expectancy. 
The Geographic Areas under analysis were the Primary Health Care Groups, called ACeS, and three Reference Areas was considered: Northern region, Portugal mainland and the "best" ACeS in terms of life expectancy at birth. The life expectancy figures were based on deaths registered and National Health Institute mid-year population estimates. A set of 30 causes of death were selected and data were extracted using the Tenth Revision of the International Classification of Diseases (ICD-10).

The breakdown on life expectancy gaps was calculated by applying methods developed by the Association of Public Health Observatories of England in the "Health Inequalities Intervention Toolkit" [3]. The methods for partitioning by cause of death and age group are similar and involve a process to make the death rates for each ACeS the same as those for the Reference Area. This requires changing the ACeS mortality rates to those of Reference and changing the Reference rates to those of the ACeS. An average of these is then calculated. These methods allow us to obtain the contribution of the different causes of death and age groups to these gaps. Also, life expectancy potential gains were estimated.

The life expectancy impact of future interventions is estimated as a percentage reduction in the main causes of death in specific age groups.

\section{RESULTS}

A tool that allows us to observe in 3-years periods the relative gap in life expectancy from 1996-1998 to 20082010, was built.

In Figure 1 it can be seen, for example, changes in life expectancy of the Reference (Northern region) and one of its Primary Health Care Groups (ACeS Porto Ocidental e Porto Oriental), with the corresponding evolution of the relative gap, for the male gender.

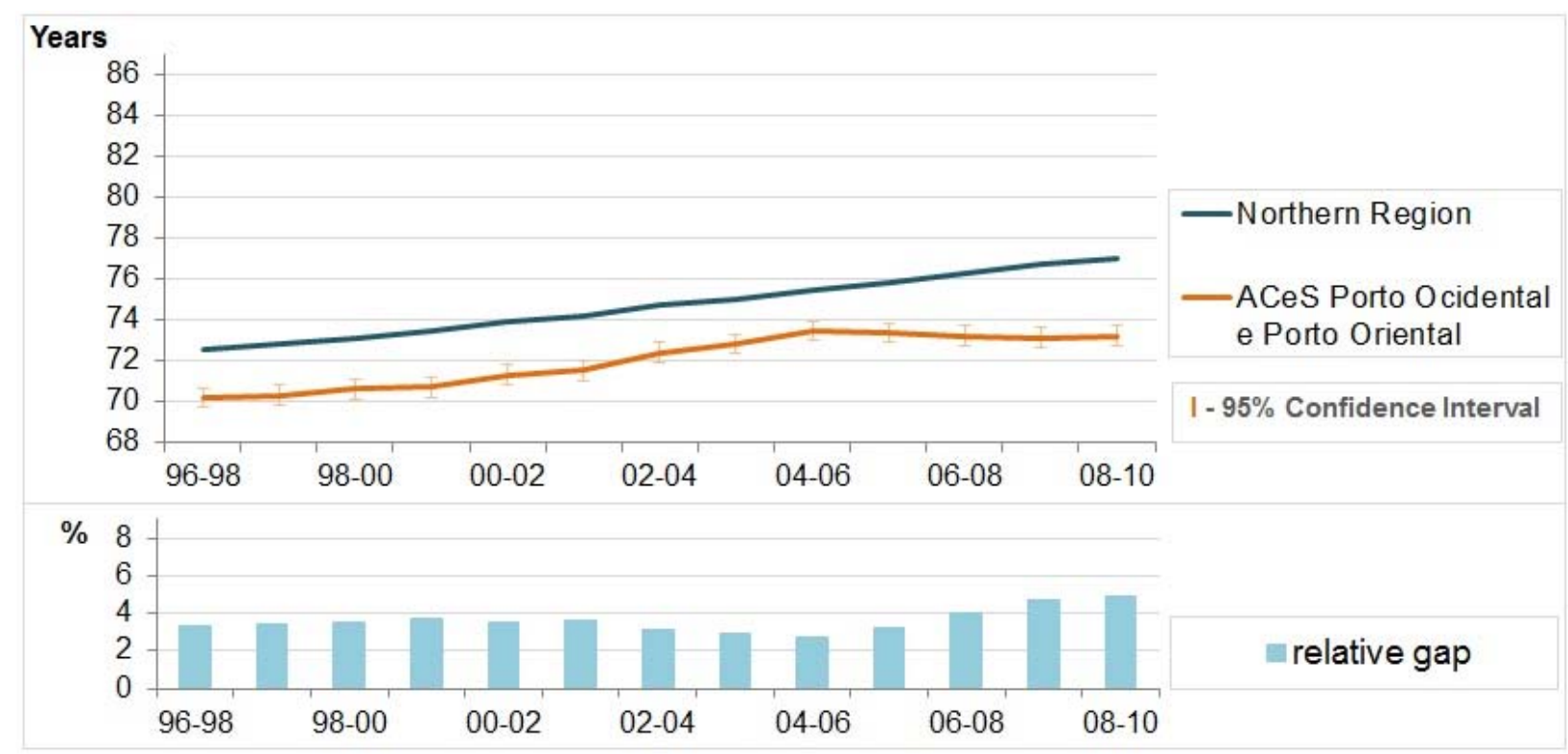

FIGURE 1. Evolution of life expectancy in the Northern region and ACeS Porto Ocidental e Porto Oriental for males, with the evolution of their relative gap.

The tool also allows to visualize the spatial distribution of different values of life expectancy at birth for each $\mathrm{ACeS}$ and its ordination to better visualize differences between them. Figure 2 shows each ACeS's life expectancy, with the corresponding ordering, to the specific 3-year period 2008-2010 and males. 


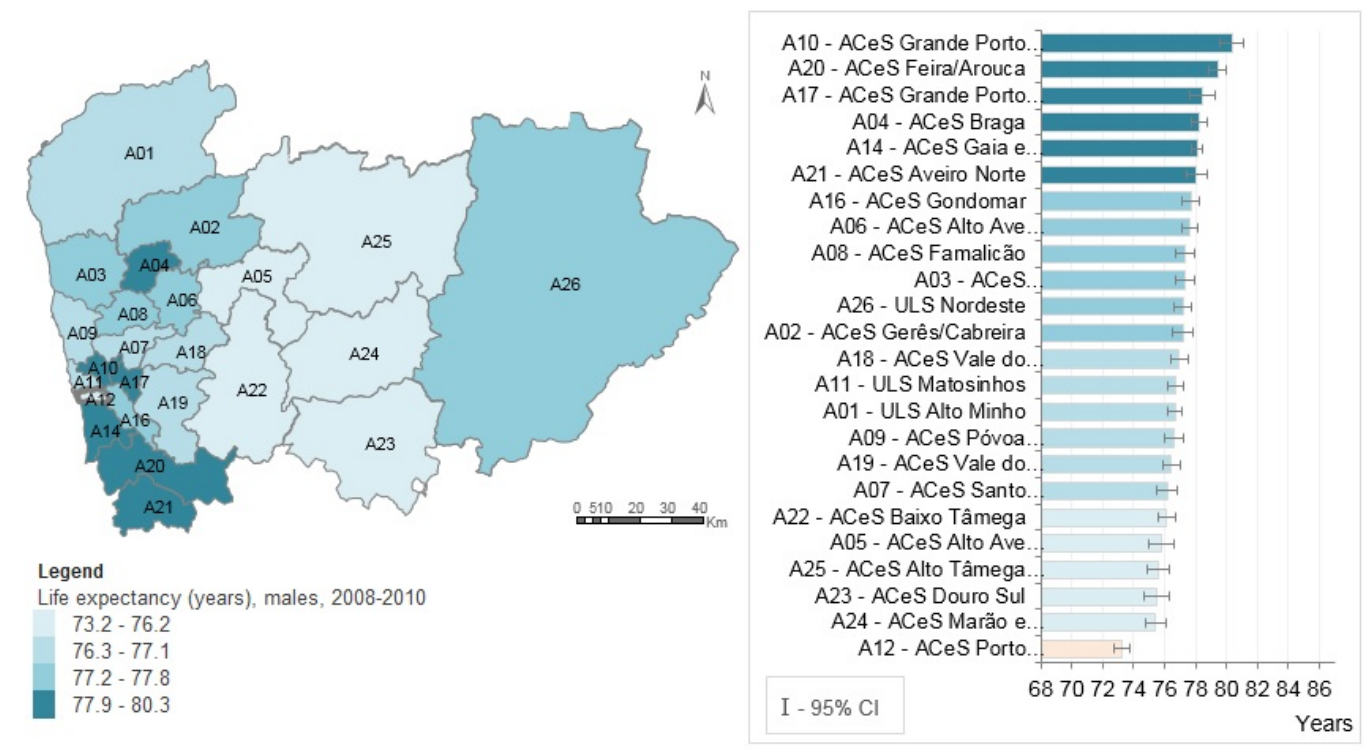

FIGURE 2. Life expectancy spatial distribution and ordering in males, 2008-2010.

For a specific 3-year period (2008-2010) the tool allows to view the contribution of diseases to the life expectancy gap (identification of health inequalities). Figure 3 shows, by gender, the breakdown of life expectancy gap between Northern Region and one of its ACeS by major groups of causes of death. In this example, despite gender differences, malignant tumors are the major contributors to the life expectancy gap, both for males and females.

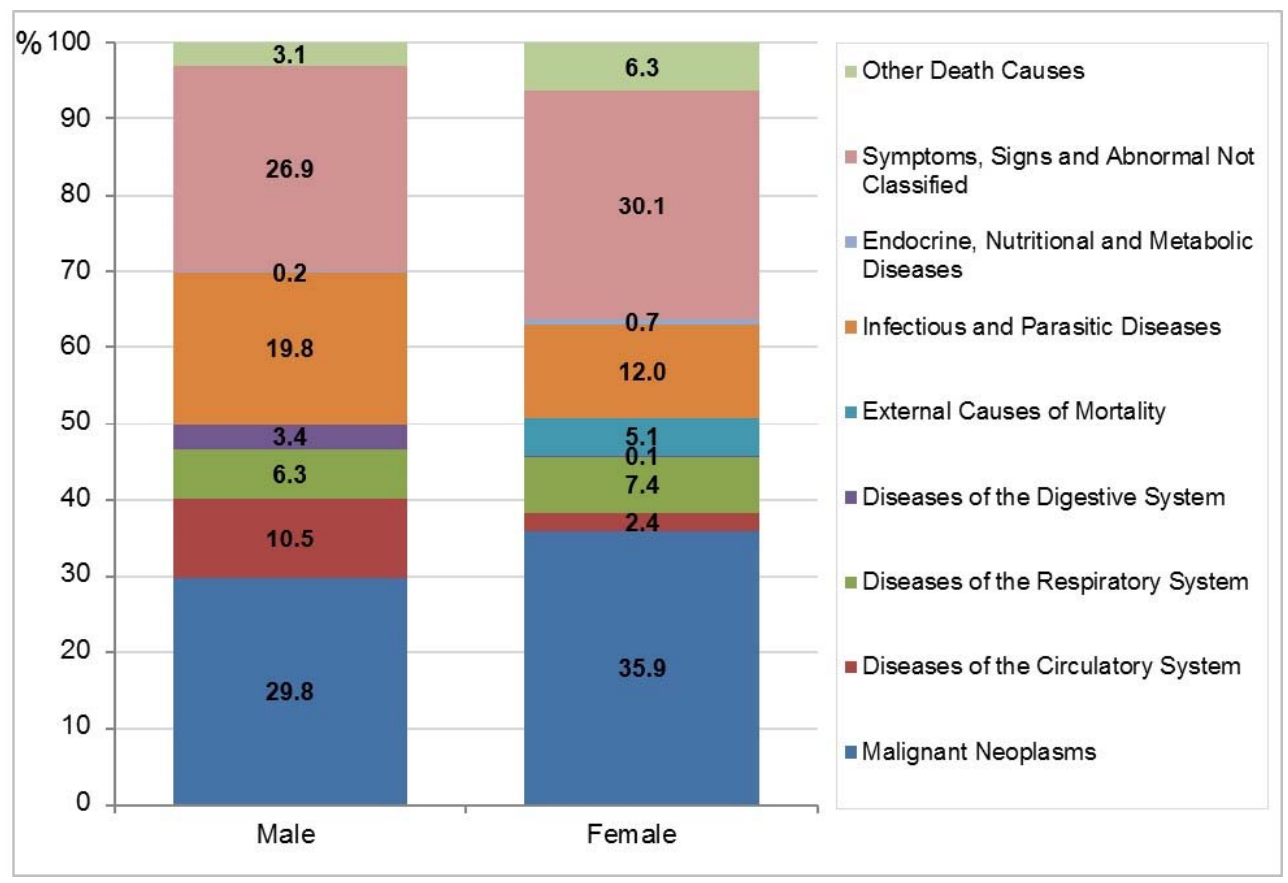

FIGURE 3. Contribution to the gap in life expectancy by cause of death.

Figure 4 presents, by gender, estimation of the life expectancy years gained if the population of this particular ACeS had the same age-specific mortality rate as the Reference (in this case the Northern region) for each cause of death. By introducing different possible percentage reductions in leading causes of death in specific age groups and estimating its impact on the improvement of life expectancy and the reduction of its relative gap, this tool allows to create different scenarios for decision-making (informing decision-making, for reduction of health inequalities). 


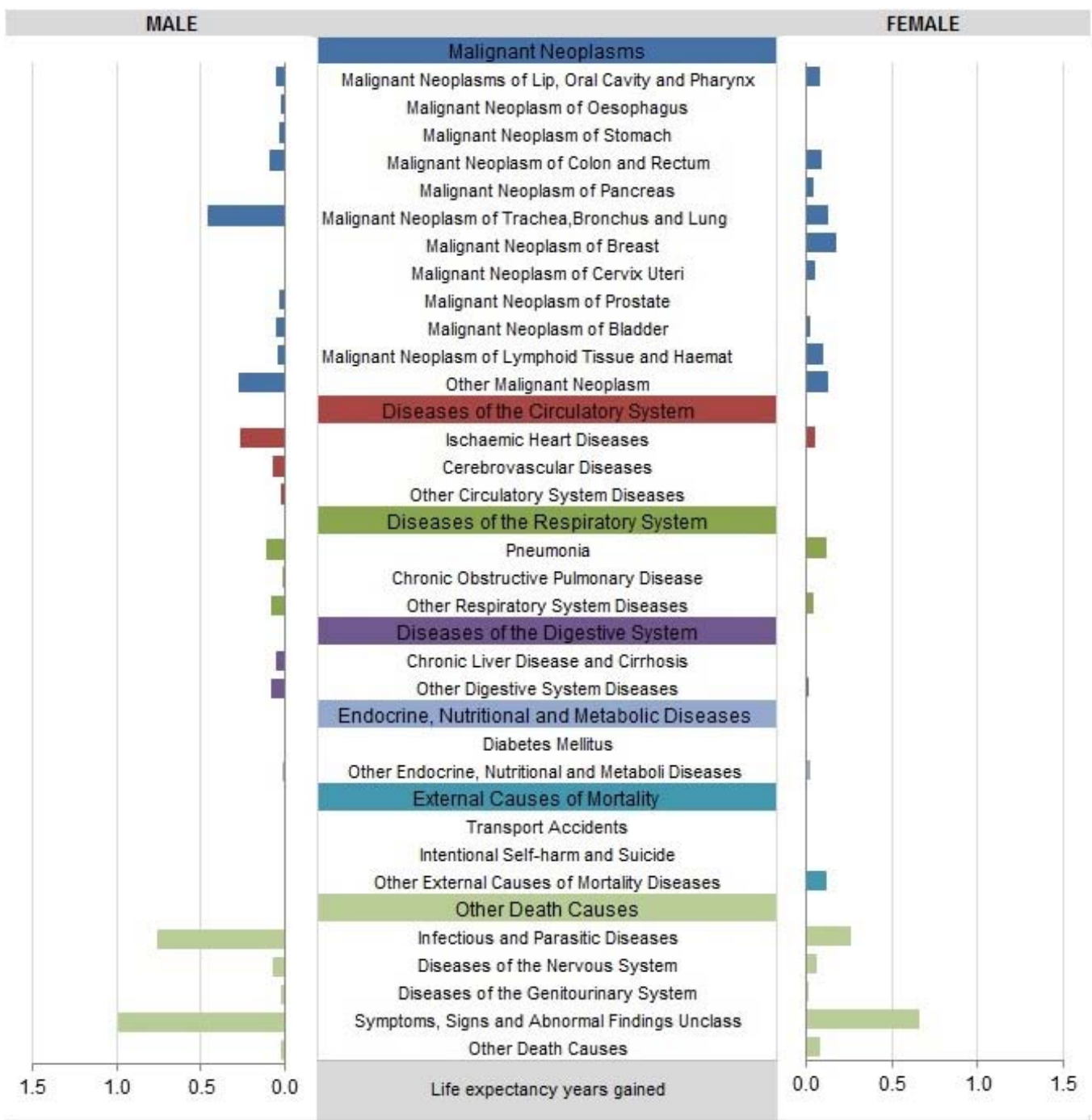

FIGURE 4. Estimation of life expectancy years gained.

\section{CONCLUSIONS}

The construction of this toolkit will enable Public Health Services at the regional and local levels to identify health inequalities and to make prognosis through the analysis of some interventions expected impact in reducing life expectancy gaps. It will also help decision-makers to promote more efficient and effective interventions. The process of constructing this toolkit is dynamic and its diagnostic, prognostic and analytical power should be improved over time. This toolkit is the first one of its kind developed in Portugal.

\section{REFERENCES}

1. C. L. Chiang, "The Life Table and its Construction." in Introduction to Stochastic Processes in Biostatistics (New York, John Wiley \& Sons, 1968), pp. 189-214.

2. M. Marmot, Fair Society, Healthy Lives [The Marmot Review] (2010). Available at: http://www.marmotreview.org/AssetLibrary/pdfs/Reports/FairSocietyHealthyLives.pdf (Accessed 01/11/2011).

3. Health Inequalities Intervention Toolkit. London Health Observatory. Available at: http://www.lho.org.uk/LHO_Topics/Analytic_Tools/HealthInequalitiesInterventionToolkit.aspx (Accessed $01 / 11 / 2011)$. 